\title{
Особенности грамматикализации предметных имён-квантификаторов неопределённо-большого количества в современном английском и русском языках
}

Термин «грамматикализация» был впервые введен Антуаном Мейе в начале XX в. в статье 1912 г. «Эволюция грамматических форм». По мнению Рахилиной сущность грамматикализации состоит в том, что некоторое языковое выражение приобретает новую грамматическую функцию, при этом сфера его употребления сужается: лексема или словосочетание начинает употребляться только при определенных грамматических условиях и более ограниченно, чем в исходном значении; это грамматически ограниченное употребление сопровождается изменением или сужением исходного значения и превращением его из лексического в грамматическое (ABBYY Lingvo x5).

Вопросы, касающиеся эволюции языка, изучены в многочисленных исследованиях, выполненных на материале различных языков и посвящённых изучению теории граммматикализации и т.д. (Lehmann 1982; Heine, Reh 1984; Heine et al. 1991; Hopper, Traugott 1993; Heine, Kuteva 2002; Bybee, Dahl 1989; Майсак 2002).

Настоящее исследование посвящено особенностям грамматикализации квантификативной лексики современного английского и русского языков. Объектом данного исследования являются предметные имена, которые в исходном своем значении обозначают конкретные предметы, но в предложной генитивной конструкции $\mathrm{N}$ of $\mathrm{N}$ подвергаются семантическому сдвигу, частично грамматикализуясь, теряют часть своих исходных признаков и приобретают количественное значение, т.е. становятся квантификаторами неопределенно-большого или неопределенно-малого количества.

Необходимо учесть, что понятие количества и квантификации не являются тождественными (ABBYY Lingvo x5). Квантификация представляет собой любое измерение объекта наименования: квантификация по количеству - «сколько», величине объекта наименования, по параметрам «большой - маленький» и т.д.; интенсивность; степень и т.п.; понятие собирательности; длительности протекания, повторения у глаголов (Allen 2000: 71). 
Например, raft (a simple flat boat made by tying long pieces of wood together) (плот во фразе $a$ shower of smth (множество ч.-л.)) уже обозначает не предмет, а количество объектов (ср.: A whole raft of people came to the wedding - / На свадьбе было полно народа (АВВYY Lingvo х5). Квантификаторы - это слова, отвечающие на вопрос «Сколько?», т.е. вербализующие концепт КОЛИЧЕСТВА.

Цель настоящей работы состоит в исследовании предметных имен, вербализующих концепт неопределенно-большого количества в современном английском и русском языках, посредством проведения сопоставительного анализа степени грамматикализации квантификаторов неопределенного количества. В связи с этим одна из основных задач на данном этапе заключается в том, чтобы выявить их различия по степени грамматикализации, а также особенности грамматикализации квантификаторов неопределенно-большого количества.

По нашим подсчетам список квантификаторов весьма значителен и содержит в общей сложности 71 лексему.

Квантификаторы неопределенно-большого количества в современном английском языке (36 лексем):

avalanche, bag, barrage, battery, bucket, bunch, cloud, deluge, epidemic, flood, forest, fusillade, inundation, nail, heap, lake, load, mountain, ocean, pile, raft, rain, rash, reservoir, river, sea, shower, spate, stack, store, stream, swathe, torrent, volley, wave, world (ABBYY Lingvo x5) / лавина, мешок, шквал, набор, ведро, группа, облако, потоп, эпидемия, наводнение (ливень), лес, стрельба, паводок, ноготь, груда, озеро, груз, гора, океан, кипа, плот, дождь, сыпь, бассейн, река, море, ливень, половодье, скирда, склад, ручей, бинт, поток, залп, волна, мир.

Квантификаторы неопределенно-большого количества в современном русском языке (35 лексем):

арсенал, батарея, бездна, букет, воз, ворох, гора, град, громада, груда, дождь, куча, лавина, лес, ливень, масса, мириадь, море, океан, орава, орда, полчище, поток, прилив, пропасть, прорва, река, рой, толпа, туча, тьма, уйма, фейерверк, фонтан, шквал.

В настоящие списки входят лишь предметные имена, но не все слова допустимые в предложной генитивной конструкции со значением «много» или «мало» типа host, regiment, crowd (ABBYY Lingvo х5) / множество, масса, толnа и пр., так как их исходное значение уже подразумевает множество и связанную с ним идею большого количества. Полный список квантификаторов включал бы все слова, возможные в предложной генитивной конструкции со значением «много» или «мало» (например, slew, deal, profusion, puff, (ABBYY Lingvo x5) / масса, некоторое количество, избыток, порыв и пр.), но их анализ выходит за рамки нашего исследования. 
Важно заметить, что не все лексемы имеют возможность грамматикализации, диапазон подобных лексем-источников весьма ограничен. Однако в различных языках существуют определенные лексические единицы, особенно часто подвергающиеся грамматикализации: так, источниками предлогов часто являются слова, обозначающие части тела, источниками артиклей - указательные местоимения, источниками видовременных показателей бытийные глаголы, глаголы движения и пр. (см. подробнее: Heine, Kuteva 2002). Таким образом, при изучении процессов грамматикализации в каком-либо языке необходимо в первую очередь сконцентрироваться на словах определенных лексических групп.

Согласно Майсак Т. А. человек стремится к тому, чтобы осмыслить нефизическое в терминах физического, в силу чего концептуализация физической сферы опыта выступает в качестве базовой. Грамматикализация же содержательно представляет собой частный случай семантических изменений, в каком-то смысле - развитие полисемии у определенной лексемы. При этом нас в данном случае интересуют не все пути семантической эволюции, а лишь те, при которых итоговое значение попадает в универсальный грамматический набор.

Можно говорить об эволюции лексического элемента в сторону грамматического как о некотором пути грамматикализации (ср.: английские эквиваленты - path или channel of grammaticalization). В идеальном случае путь этот можно представить себе как имеющий начало и конец: будем, соответственно, говорить об источнике грамматикализации (которым является лексическая единица или, точнее, конструкция) и ее результате (грамматическом показателе). Грамматикализация является процессом градуальным, так что существуют «более» и «менее» грамматикализованные показатели (Майсак 2000).

В ходе грамматикализации, т. е. появления новой грамматической функции, происходят два главных процесса: сдвиг значения и декатегоризация - это верно и для рассматриваемой нами именной генитивной конструкции: в ней происходит декатегоризация (превращение из предметного имени в квантификатор) с частичной потерей (или «выветриванием») исходного лексического значения и одновременно рекатегоризация с появлением нового значения из универсального грамматического набора (Плунгян 2000: 17), которым определяются новые ограничения, в том числе сочетаемость внутри конструкции (Плунгян 2004).

Таким образом, согласно гипотезе Ли Су-Хён, можно установить следующие этапы грамматикализации как процесса семантического перехода от предметного имени к квантификатору:

1. образование окказиональной метафоры;

2. закрепление ее в определенном узком лексическом контексте в составе конструкции, в данном случае - генитивной (= лексикализация); 
3. постепенное - через отождествление предметных множеств с абстрактными - включение в сочетаемость абстрактной лексики;

4. дальнейшее расширение употребления конструкции, с охватом имен лиц - вплоть до снятия всех сочетаемостных ограничений;

5. одновременно - стирание, или „выветривание” исходного значения (англ. термин bleaching);

6. итог, или полная грамматикализация, т. е. превращение имени в полноценный квантификатор.

Каждый лексический квантификатор находится на своем этапе грамматикализации и по-своему ограничен в сочетаемости. Такие ограничения практически всегда связаны с «памятью» квантификатора об исходной лексеме, претерпевшей семантический сдвиг.

Но проблема связи исходного и производного значений имеет два разных аспекта:

1. Условно его можно назвать «диахроническим»: он ставит во главу угла исходное значение слова и предлагает установить, какова должна быть семантика имени-источника, чтобы интересующий нас семантический сдвиг стал возможен и возник количественный квантификатор.

2. Условно говоря, «синхронный»: что остается в семантике лексемы после того, как сдвиг произошел и часть исходного значения «стерлась».

Переходя в квантификативную зону, предметные существительные втягиваются в процесс грамматикализации; однако степень грамматикализации квантификаторов неодинакова, на что указывают их сочетаемостные ограничения.

В статье Е. В. Рахилиной и Ли Су-Хён показано, что русские квантификаторы неравномерно распределены по степени грамматикализованности, так что оба крайних полюса этой шкалы оказываются заняты. Среди квантификаторов имеются слова, тесно связанные с исходным лексическим значением - примером здесь может служить имя копна. В квантификативных контекстах копна сохраняет идею конусообразной формы и особой структуры объекта, количество которого оценивается. Но как квантификатор копна применяется только к волосам, «похожим» на сено / солому (с которыми имя копна связано в исходном своем значении); копна волос $\approx$ 'очень много (с точки зрения говорящего, может быть, больше, чем на самом деле) волос на голове человека, которые при этом имеют форму, сходную с формой стога сена / соломы'. Поскольку семантическая связь квантификатора и определяемого имени в данном случае фиксирована, т. е. произошла жесткая лексикализация этой конструкции, квантификатор копна минимально грамматикализован.

Средней степенью грамматикализации обладают квантификаторы, сочетающиеся не только с предметными, но и с абстрактными и/или вещественными именами. 
Для квантификаторов неопределенно-большого количества это следующие имена: арсенал, батарея, бездна, букет, воз, ворох, гора, град, громада, груда, дождь, лавина, лес, ливень, масса, мириады, море, океан, орава, орда, полчище, поток, прилив, пропасть, прорва, река, рой, толпа, туча, тьма, уйма, фейерверк, фонтан, шквал.

\section{Например:}

град 1. один из видов атмосферных осадков, выпадающий небольшими ледяными шариками.

2. множество (о чем-нибудь осыпающем, поражающем; книжн.). Град пуль. Град камней. Град насмешек. Град писем. «Град колкостей и шуток ваших грянет». (Грибоедов 1986: 59)

лавина 1. снежная глыба, низвергающаяся с гор.

2. что-нибудь скопившееся в огромном количестве.

Скопилась лавина неразобранных бумаг.

Максимальной степенью грамматикализации обладает слово куча - оно сочетается и с одушевленными именами, и с именами предметов, веществ, и с абстрактной лексикой: куча людей, куча книг, куча дел, куча забот.

\section{Например:}

куча 1. то, что свалено горкой, грудой;

2. оценочная характеристика количества, множества чего-либо как чрезвычайно большого, неисчислимого.

Кучи щебня. Куча людей, народа. На мне куча забот. Он прочел кучу книг. (Даль 1990)

На противоположном полюсе шкалы, в самом ее начале находятся такие квантификаторы, которые минимально грамматикализованны и сочетаются только с вещественными именами.

Для квантификаторов неопределенно-большого количества наименее грамматикализованным является слово world. Данное имя не допускает сочетаемости с именами предметов, субстанций и с одушевленными существительными, сочетаясь лишь с несколькими абстрактными существительными, образуя устойчивые словосочетания, а именно: a world of good, a world of difference;

Например:

A change of job would do you a world of good.

There's a world of difference between the US and Europe. 
Однако, несмотря на данное лексико-фразеологическое ограничение, возможно окказиональное расширение словосочетаемости: Anyone trying to steal Death's horse soon understood the expression 'a world of hurts'. (Pratchett 1994: 153)

Средней степенью грамматикализации обладают квантификаторы, сочетающиеся не только с предметными, но и с абстрактными и/или вещественными именами.

Для квантификаторов неопределенно-большого количества это следующие имена: bag, barrage, bucket, epidemic, forest, fusillade, hail, mountain, lake, rain, rash, reservoir, shower, spate, stack, store, swathe, torrent, volley, wave.

\section{Например:}

mountain 1. a very high hill, often with rocks near the top

2. a very large amount or number_of something

He is walled in by a mountain of papers in his cluttered Broadway office (Allen 2000). / В своем загроможденном всяким хламом офисе на Бродвее он окружен горами бумаг.

shower 1. a brief and usually light fall of rain, hail, sleet, or snow

2. a very large amount or number of something

A shower of dust sprinkled his face (Allen 2000). / На лицо ему попало много пыли.

Среди английских квантификаторов неопределенно-большого количества наиболее грамматикализованны: avalanche, battery, bunch, cloud, deluge, flood, inundation, heap, load, ocean, pile, raft, sea, river, stream.

Например:

bunch 1. a number of things of the same type which are growing or fastened together; a group of people (informal)

2. a large amount of something; a large number of things or people.

I had done a bunch of laundry; I had piles and piles of it and I did it all in one day (Тухтаходжаева 1981: 237). / Я устроил большую стирку; у меня были целые горы белья и я постирал все за один день.

ocean 1. a very large expanse of sea, in particular each of the main areas into which the sea is divided geographically

2. a vast expanse or quantity of something

Laura found herself - in a full ocean of doubt and fear (The Dublin University Magazine 2010: 578). / Лаура обнаружила, что полна сомнений и страха. 
Интересно заметить, что квантификаторы неопределенно-большого количества никогда не используются в отрицательных конструкциях (a sea of faces $-*$ not a sea of faces).

Таким образом, в ходе сопоставительного анализа степени грамматикализации квантификаторов неопределенно-большого количества мы обнаружили, что число квантификаторов неопределенно-большого (20) количества, сочетающихся с абстрактными именами, одинаково, что объясняется действием регулярной метафоры: объем свойства или состояния отождествляется с количеством вещества.

Мы также выяснили, что квантификаторы неопределенно-большого количества представлены большим числом имен, обладающих высокой степенью грамматикализации (15). В то время как квантификаторы неопределенно-малого количества имеют лишь двух «представителей» fraction, trickle.

Среди квантификаторов неопределенно-большого количества с минимальной степенью грамматикализации можно выделить лишь одну лексему world, причем, данное имя обладает строгой фразеологической закрепленностью, в то время как зона квантификаторов неопределенно-малого количества представлена большим разнообразием (6).

Дальнейшее изучение квантификаторов предполагает сопоставительное исследование таких их характеристик как качественных параметров, синтаксического поведения, а также английской, французской и русской зон квантификативности.

\section{Библиография}

Грибоедов А. С. (1986), Горе от ума, Москва: Правда, 123 с.

Даль В. И. (1990), Толковый словарь живого великорусского языка: т. 3, Москва.

Майсак Т. А. (2000), Грамматикализащия глаголов движения: опыт типологии, «Вопросы языкознания», № 1.

Плунгян В. А. (2000), Общая морфология: Введение в проблематику, Москва: Эдиториал УРСС, $384 \mathrm{c}$

Рахилина Е. В., Ли Су Хён (2009), Семантика лексической множественности в русском язы$\kappa е$, «Вопросы языкознания», Москва, с. 13-40.

Тухтаходжаева 3. Т. (1981), Выражение категорий квантификации и оценки в словообразовательной системе современного английского языка, Москва, $204 \mathrm{c.}$

ABBYY Lingvo x5: [Электронный ресурс] ABBYY, Lingvo-2011, Электронная библиотека.

Allen M. (2000), The Rooms of Heaven: a Story of Love, Death, Grief, and the Afterlife, Vintage, $336 \mathrm{p}$.

Collins Dictionary English Definition and Synonyms [Электронный ресурс], URL: http:/ dictionary. reverso.net/english-synonyms/ (дата обращения: 20.03.2014).

Heine B., Kuteva T. (2002), World Lexicon of Grammaticalization, Cambridge: Cambridge University Press, $387 \mathrm{p}$.

Pratchett T. (1994), Soul Music, Gollancz, 288 p.

The Dublin University Magazine (2010), BiblioBazaar, Vol. 92, 794 p. 
Ksenija Aksjenova

The pecularities of grammaticalization of quantifiers expressing an indefinitely large amount in the English and Russian languages

\section{Summary}

The article presents the comparative analysis of quantifiers of indefinitely large amount in the English and Russian languages. The author reveals the levels of grammaticalization among quantifiers. The very process and various stages of grammaticalization in the compared languages are described in detail. Finally, the conclusions are drawn on the similarities and differences of grammaticalization levels in the English and Russian languages. 